\title{
HUMAN PERCEPTION AND INTERPRETATION OF COLOUR TERM IDIOMS THROUGH THEIR ORIGINS
}

\author{
Vesna Waite \\ Private School of English "Dorothy” 8 mart 19A, Niš, Serbia \\ E-Mail: vesna.waite77@gmail.com
}

\begin{abstract}
The subject of the analysis in this paper is the relation of colours and colour idiomatic expressions to the human mind perception and their correct interpretation resulting from this relation. Both associations of colours and the origins of colour idioms can contribute to a better comprehension of the actual meaning of the colour idioms. Reflexive associations colours have to the human mind, in some cases being correct and in others the association being shifted to different meaning, lead to the proper translation or impose difficulties for the correct translation in which case the etymology could be of great assistance in proper interpretation. This paper consists of two parts: the theoretical part and the analytical part. In the theoretical part the semantic properties of idioms as grammatical units are represented for the purpose of a better comprehension of their structure. Berlin and Kay (1969) presented the theory in their study "Basic Colour Terms: Their Universalities and Evolution" which is included in the paper as a way of establishing the manner in which the human mind perceives colours. In the analytical part, the influence of certain colours on the way the human mind perceives them and interprets the colour idiomatic expressions is analyzed through association shifting, literal transferability and variations of associations among various languages. The method used in the research is direct sampling from dictionaries, and the data was studied by the use of etymological and structural analysis. Representative samples of colour-based idioms were chosen from the lexicon of idiomatic expressions commonly used in the English language. The purpose is to demonstrate the degree of flexibility of the perception of colour within the idiomatic expression.
\end{abstract}

Key words: colour idioms, etymology, human mind, perception, idioms, origins, transferability

\section{INTRODUCTION}

The human mind constantly faces the challenge of interpreting the metaphorical layer of language that employs idiomatic expressions. Certain emotions, states and situations are expressed through the use of idiomatic phrases for the purpose of reflexing their correct meaning as precisely as possible. One of the ways the mind generates the idiomatic expression is by making a colouristic element a constituent part of the idiom whereby in some cases the comprehension is facilitated by using intuition but when the colour association is shifted from its usual context the mind is misled to interpret it in an incorrect way. The illustrations given for this occurrence are the colour white and some of the Shakespearean idioms containing green as its colouristic element. There are various reasons for this, one of which is the distant origin of the expression that is now forgotten; however, 
it is still employed due to the fact that it is ingrained in language and the mind accepts it as correct in its usage. As the insight into the perception of colours by the human mind, Berlin and Kay's study Basic Colour Terms: Their Universalities and Evolution (1969), in which around hundred languages were examined with regard to colour terminology, is included. The idioms selected for this paper were taken directly from dictionaries and explored in detail in order to establish the relation colours and their associations have to the correct interpretation analyzing them through their etymology which can be of great assistance in the cases when the mind encounters the problems of incorrect interpretation due to the nonexisting equivalence between associations and their interpretation.

\section{DESCRIPTION OF IDIOMS}

The language used to express everyday experience comprises largely the metaphorical layer which is the essence of idioms where word elements forming the idiom do not retain their original meaning. The meaning of the construction goes well beyond the literal meaning of the words as separate units. According to Brenner (2003, 50-51), "Idioms have a meaning that is different from or extends the literal meaning of the individual word or words. Idioms break or stretch the rules of grammar, word order (syntax), and semantics to a certain degree. Idioms change meaning when translated word for word into another language." Idioms are expressions of various structures and therefore usually grouped in relation to different criteria. For instance, they can be divided into groups of idioms whose main components are various word classes, such as adjectives, verbs, prepositions, etc. The other way of organizing them is on the basis of their metaphorical layer, according to a topic and a key word. In this paper, the idioms are organized according to a topic, namely, colour.

\section{SEMANTIC STRUCTURE OF IDIOMS}

According to Palmer $(1976,98)$, "In semantic terms, idioms involve a collocation of a special kind". He argues that idioms comprise collocations for individual words but the meaning of the resultant combination is sometimes rather difficult to comprehend. It does not relate to the meaning of any word in particular but its meaning goes beyond the meanings of its separate words. It is, more often than not, closer to the meaning of a single word. For instance, in an idiom comprising a verb, an adjective, and a noun "to show the white flag", the meaning is closer to one word, and that is "to surrender". However, even when the meaning of an idiom is a single word, it does not function as one word. Thus, when forming the past tense, it would never be said "show-the-whiteflagged" but the tensed word would be the verb "to show" as in a normal sequence of grammatical words, forming "showed the white flag" instead ("Our opponents held all the cards tonight, so we showed the white flag and left early" [Ammer, 2013, 495]). In the case of the idioms comprising a verb and a noun, the verb can take the past tense but the number of the noun cannot be changed. So, in the same idiom "show the white flag" it is not possible to say "show the white flags ". Likewise, idioms containing an adjective and a noun, as in the idiom "brown bagger", which is assigned to "a person who brings his or her own supplies" ("The architects of the new office designed a space for brown baggers to eat lunch" [Ammer, 2013, 59]), the number of the noun can be changed so that "brown baggers" is perfectly acceptable, as seen in the example above; however, the 
comparison of adjectives is not allowed, so the expression "browner bagger" is not possible. Another semantic characteristic of the idioms is that in the instance of some idioms, like "to catch someone red-handed" forming the passive voice is grammatically correct ("The thief was caught red-handed as she was emptying the till" [Oxford Idioms Dictionary for Learners of English, 2006, 54]). However, in the case of the idiom "to scream/yell/cry blue murder" the meaning of which is "to protest wildly and noisily" (Hornby, 1989, 119), the passive structure cannot be made; a blue murder cannot be either screamed, yelled, or cried. An even more absurd construction is formed with "the pot calling the kettle black", this idiom being defined as "accuser having the same fault as the person he is accusing" (Hornby, 1989, 967). When transforming the active sentence into the passive one, the construction "the kettle called black by the pot" is grammatically correct but, stylistically, its use is highly questionable.

\section{BERLIN AND KAY HYPOTHESIS}

One of the most important studies concerning colour terminology was conducted by Brent Berlin and Paul Kay in 1969, the result of which was the book Basic Colour Terms: Their Universalities and Evolution, in which they examined and compared the colour terminology of almost a hundred languages. The conclusion they came to is very precise, stating that there exist eleven colour categories making up a universal set whereby every language takes a subset. These colour categories are as follows:

Table 1 Berlin and Kay’s Ordering of Colours

\begin{tabular}{|c|c|c|c|c|c|c|c|c|c|c|}
\hline $\begin{array}{l}\text { white } \\
\text { black }\end{array}$ & $<$ & red & $<$ & $\begin{array}{l}\text { green } \\
\text { yellow }\end{array}$ & $<$ & blue & $<$ & brown & $<$ & $\begin{array}{l}\text { purple } \\
\text { pink } \\
\text { orange } \\
\text { grey }\end{array}$ \\
\hline
\end{tabular}

One of the most important aspects of the results of their study is their statement that those categories appear in every culture in this particular order. "... there is a natural hierarchy among at least six of these focal areas which determines their lexicalization in any language" (Lyons, 1977, 246). "To the hypothesis, so far stated, Berlin and Kay (1969) add a further "evolutionary" hypothesis which states that the types of vocabulary as ordered above represent a fixed sequence of historical stages through which a language must pass as its basic vocabulary increases" (Leech, 1974, 236). This particular order is important because of the way the human mind starts perceiving colours. They argue, although this argument is subject to confirmation, that children acquire colour terms in this particular order. All of these conclusions are fundamentally important for the manner in which the human mind perceives colours, and there is yet another important issue they state. Berlin and Kay (1969) argue that people are able to perceive the focus of a colour range in an easier and more definite way than the border area of the colour range, which is why colour terms should be given according to the colour range foci and not to the periphery of the colour range. This is why it is not possible to translate colours in the same way in different languages. The hues which belong to these peripheral areas are subject to different translations in different languages. However, the basic colours, 
identifiable by the foci, coincide in different languages and, accordingly, can be translated properly (Leech, 1974).

\section{PERCEPTION OF COLOURS AND IDIOMS IN THE HUMAN MiND}

Colour term idioms are colour related expressions whose meaning goes well beyond their literal denotation, making the idiom and the colour contained in it interpretable in completely different ways. The human mind starts perceiving colours at an early age, associating them with various emotions, sensations and experiences. These colour associations stay retained in human mind later in life, shaping the perspective individuals take on the world they live in. The mind attaches characteristic ideas, emotions and connotations to colours. Colours can have positive associations and may also convey negative connotations, light colours being known for helping people feel more relaxed while the darker ones create bleaker and more pessimistic associations. Colours black and white, being referred to as achromatic, meaning "without colour" (Collins, s.v. "achromatic", accessed on 25 February, 2019, https://www.collinsdictionary.com/dictionary/english/achromatic) because of their not belonging to the colour spectrum length could be argued not to be colours at all, only the presence of light (white) and the absence of light (black). However, since they were considered proper basic colours in Berlin and Kay's (1969) theory, which this paper uses to establish the way colours are perceived, they are going to be dealt with together with the other colours. White is the colour that engenders positive feelings in the human mind, like purity, cleanliness, and innocence. Black, on the other hand, being the antipode of the colour white evokes negative emotions, such as sadness, remorse, evil, disgrace, and mourning. One of the examples of how the mind perceives colours black and white is the Western film genres deployment of these colours using white to signify good and black to signify bad. The "goodies" would wear white hats and the "baddies" would naturally wear black hats. In this way the spectator's perception of positive and negative is reflexive. The colour red increases enthusiasm, excitement, stimulates energy, etc. It is, however, also associated with anger, fury, and embarrassment due to the physical manifestation of these emotions on the person's face. Colours blue and green both convey tranquility, associating human mind with nature, blue being associated with the blue sky and water and green with the colour of grass and leaves. Green can also refer to numerous metaphors such as young and new, perceived in a positive way but on the other hand also immature and inexperienced, perceived in a negative way. However, in English, the association given to green in colour-related idioms is usually shifted to jealousy. Yellow is the colour that appears in the fewest idiomatic expressions. Although it could be expected to be associated with optimism and joy, it is usually associated with cowardice and illness.

\subsection{Shifted Associations}

The antipodal relationship of colours is particularly noticeable in colours black and white (Lyons, 1977). White is expected to denote optimistic and positive associations whereas black, on the other hand, is supposed to be perceived as a colour of negative connotations. The instance of the idiom containing white that indicates the purest, the most innocent associations could be "a white lie" which refers to a small, insignificant lie, "told to spare feelings or from politeness" (Ammer, 2013, 495). Contrary to expectation, there are some idioms related to white associated with negative feelings and characteristics, such as "a whited sepulchre". This idiom refers to "a hypocrite, someone 
who is ostensibly virtuous but inwardly corrupt" (Siefring, 2004, 312). The origin of this idiom stems from the Bible, connecting the colour white with the whiteness of bones and the corpse, and therefore uncleanliness: "Woe unto you scribes and Pharisees, hypocrites! for ye are like unto whited sepulchres, which indeed appear beautiful outward, but are within full of dead men's bones, and of all uncleanness." (Matthew 23:27). Another idiom with the colouristic element of white that evokes negative associations is "a white elephant". The meaning of the idiom can be extended to "a thing that is useless and no longer needed, although it may have cost a lot of money" (Oxford Idioms Dictionary for Learners of English, 2006, 446). This expression derives from the ancient royal Siamese practice of seeking to impoverish a subject who had incurred their displeasure. The king would bestow upon such a subject a sacred albino elephant which could not be slaughtered but whose maintenance was very expensive and would ruin the subject financially (Ammer, 2013). This idiom illustrates perfectly the fact that the meaning of an idiom is not predictable from the colour itself and may not be reflexively interpreted correctly. There are also many English idioms whose etymology is so distant from other cultures that they cannot be interpreted literally. "A black hole" or sometimes the whole expression "Like the black hole of Calcutta" (the meaning of which is "a wretched prison cell or other place of confinement" [Ammer, 2013, 45]) is another such idiom whose etymology stems from an event in Calcutta, India, a colony of the British Empire, in 1756. A hundred and forty-six Europeans were imprisoned in such a confined space causing the death by suffocation of all but twenty-three of them (Ammer, 2013). The veracity of the event has been debated by historians since, making continued usage of the idiom questionable. However, the idiom remains engraved in the minds of people notwithstanding the fact that the accounts of the event may not be accurate. The idioms with colouristic element of black associated with negative feelings or characteristics are numerous. Contrary to those with white, which can have the associations not instinctively expected, that is, they can carry the shifted, negative associations, the ones containing black are almost always reflexively connected with the expected negative associations. The clearest example of the antipodal relationship of black and white where the association of white is shifted is the set of antipodal idiomatic expressions "black out" and "white out". In this set both black and white have a negative connotation. They both relate to the lack of visibility, the former one owing to the loss of electricity (Ammer, 2013), which the mind perceives as total blackness, and the latter one "owing to snow or fog" (Collins English Dictionary, s.v. "white out," accessed on January 30, 2019, https://www.collinsdictionary.com/dictionary/english/white-out), which is perceived as whiteness. Since the perception of colours black and white themselves is antipodal, it would be expected for their interpretation to be antipodal as well. However, as the result of the mind shifting the positive association of white to negative, the interpretation of these colours is similar, and that is negative.

\subsection{Omitted referent}

Another instance of accentuating the importance of the interpretation of idioms through their origin is the idiom structure where the referent is completely omitted, leaving only the colouristic element to carry the meaning. One example of such idioms is the idiom containing the colour red, this idiom being "in the red". "This phrase alludes to the early bookkeeping practice of marking debts in red ink and credits in black ink" (Ammer, 2013, 239). The lacking referent in this idiom is obviously ink so instead of the 
idiom being made "in the red ink", the idiom is left with only the colour designating the meaning. This idiom has its counterpart in the idiom "in the black", where the lacking referent is also ink, and the meaning of which is the description of someone who is debtfree. This idiom set shows how the mind perceives red, as opposed to black, as the signifier that stands out against the background of white, seen also in marking the students' mistakes with red pen to designate the significance of the presence of errors.

\subsection{Variations of Associations among Different Languages}

Many languages use colour red to refer to anger. In the English language the idiom "to see red" is utilized, originating from the belief that everything seems blood-coloured to a person who is very angry. Ammer (2013) argues that "it probably refers to the longstanding association of the colour red with passion and anger [Colloquial; c.1900]" (Ammer, 2013, 393). The most common association when encountering a person whose face is red is that of anger. Since this is true for all the humans regardless of the language they speak, it is expected that the same colour term would be used among different languages. However, the Italian language uses idioms with the colour green to refer to anger among which the most noticeable are "essere verde per il mal di fegato" (to be green because of liver pain) and "verde d'invidia, di rabbia" (green with envy, anger). (Dizionario di Italiano Online - La Repubblica, s.v. "verde di rabbia," accessed on February 25, 2019, https://dizionari.repubblica.it/Italiano/ $\mathrm{V} /$ verde.html). As it can be noticed, the referent used in Italian is liver. It is widely known that liver excretes bile, green in colour, when one is agitated, which is why green is used in the most common idiom used for anger "verde di rabbia". In the case of this idiom, what occurs is that the referent, the liver bile, is omitted. In this way, the mind can mistake the physical phenomenon happening inside the body for physical manifestation on the person's face, in this case resulting in rather unusual and completely incorrect image in the mind, which is that of a green face. The mere fact that different colours are used in different languages to designate the same notion leads to the conclusion that the origin of colour idioms is important for their correct interpretation.

\subsection{Transferability of Idioms}

Colour blue has a noteworthy metaphorical meaning in the phrase "blue-blooded" describing someone of aristocratic or noble birth, according to Ammer (2013). This idiom is actually a literal translation of Spanish "sangre Azul", which is used in the Spanish language to describe an aristocrat who does not have any ancestor intermarried with Moors implying the association of blue-bloodness with the colour of their veins which were more prominent due to their light skin. The expression entered English in the early 1800s and was satirized by W.S.Gilbert in Iolanthe, in which the mere possession of aristocratic title does not necessarily imply virtue (Ammer, 2013). "Blue blood! Blue blood! When virtuous love is sought thy power is naught, though dating from the Flood, blue blood!" (as cited by Ammer, 2013, 48). This idiom is one of the idioms that entered the lexicon of many other languages and can easily be interpreted in those languages. There are also instances of English idioms that entered other languages and stayed there as fixed metaphorical expressions. The English idiom that can be used as an example of such idiomatic expressions is "yellow journalism". As of December, 23, 2018, Encyclopaedia Britannica defined the idiom "yellow journalism" on its website as "the use of lurid features and sensationalized news in newspaper publishing to attract readers 
and increase circulation" (Encyclopedia Britannica, s.v. "yellow journalism," accessed on December 23, 2018, https://www.britannica.com/topic/yellow-journalism). In 1890's the rivalry between the two newspapers in New York City, The World and The Journal, was at its height, both of them exploiting sensationalist news in order to attract wider audiences. A populist cartoon character called "The Yellow Kid" was published in both newspapers, being drawn by different artists, causing a furious competition between the two newspapers thus attracting an even greater audience. Due to the character's immense popularity among readers, the term "yellow journalism" was coined (Encyclopaedia Britannica, 2018). This idiom entered the lexicon of many other languages unaltered, making it universally understandable in the correct way notwithstanding the fact that people are unaware of its origin, which is why the shifted association of expected positive association of yellow to be that of joy or optimism is neglected in the interpretation.

\subsection{Shakespearean Idioms}

One of the ways idiomatic expressions come into use in language is through literary works and plays. The author especially prolific in highly imaginative expressions in his plays is Shakespeare. He would use common expressions from the language of the time, popularizing them through the plays performed at the Globe Theatre in Southwark, London and throughout the country performed by travelling troupes of actors. Some of the idiomatic expressions were actually coined by him, and through his plays, which were one of the sources of entertainment for ordinary people at the time, these expressions entered the lexicon of common usage. In time, those expressions became engraved in the minds of the people to the extent that nowadays people use these expressions without being aware of their Shakespearean origins. Among the many expressions, the most prominent are: "good riddance" from Shakespeare's play Troilus and Cressida (1996, 724), "it's Greek to me" from Julius Caesar $(1996,586)$, "you've got to be cruel to be kind" from Hamlet (1996, 697), "lie low" from Much Ado about Nothing (1996, 543), "break the ice" from The Taming of the Shrew (1996, 337), "kill with kindness" from The Taming of the Shrew $(1996,348)$, etc. There are two English idioms with green as its colouristic element that entered the English language through Shakespeare's plays, one being "green with envy" meaning "full of desire for someone's possessions or advantages; extremely covetous... Shakespeare described envy as the green sickness (Anthony and Cleopatra, 3:2), but the current phrase, dating from the mid-1800's is the one most often heard" (Ammer, 2013, 191). The other Shakespearean idiom is "green eyed-monster" where the idiom itself is jealousy personified. This expression was used in Shakespeare's play Othello where Iago says" O! Beware, my lord of jealousy; it is the green-eyed monster which doth mock the meat it feeds on" (as cited in Siefring, 2004, 129). Colour green is usually associated with nature, youth and generally positive feelings, but after those idioms started to be used with reference to jealousy, the human mind began associating the colour itself with jealousy thus shifting its usual association.

\section{CONCLUSION}

During the research, a range of idiomatic expressions containing a colour element was analyzed. The results indicated that the shifting of associations, transferability, and variations of associations among different languages occur frequently in everyday 
speech. The occurrence of shifting colour associations in the mind is indicative of attributing different, sometimes opposed associations to the reflexive perception of colours resulting in the problematic comprehension of the metaphorical meaning. The phenomenon of colour idiomatic expressions entering other languages shows how when the mind encounters the problem of not having the precise way of expressing a certain emotion, state or situation, it is subconsciously inclined to take an existing expression not present in its lexicon. The mind can be misled to interpret negatively colours in the colour term idioms that usually have positive associations and vice versa due to the origins of those idiomatic expressions. The reason for this can be the omitted referent in the idiom, the long-forgotten event which led to the formulation of the expression, the occurrence of the colour in the idiom in the famous work of literature that was read or heard on stage often enough to become engraved in the mind. It can also result from mistaking the colour that refers to occurrence within the body for the colour of physical manifestation on the body thus creating an incorrect image in the mind.

In order to convey the most precise expression of an emotion, state or situation, the mind uses myriad means among which the metaphorical expression is one of the most frequently employed. These expressions can involve coloristic element as colour sometimes conveys particular associations in the mind that do not occur in other forms of expression. However, as colour based idioms are subject to misinterpretation, a critical awareness of the origins of those expressions can be of great assistance in understanding the context within which colour idioms are used and the significance of the variable function that colour performs within them.

\section{REFERENCES}

Ammer, Christine. 2013. The American Heritage Dictionary of Idioms. 2nd ed. Boston: Houghton Mifflin Harcourt Publishing Company.

Berlin, Brent, and Paul Kay. 1969. Basic Color Terms; Their Universality and Evolution. Berkeley, California: University of California.

Brenner, Gail. 2003. Webster's New World American Idioms Handbook. New Jersey: Wiley Publishing, Inc.

Dizionario di Italiano Online - La Repubblica, s.v. "verde di rabbia," accessed on February 25, 2019, https://dizionari.repubblica.it/Italiano/V/verde.html

Hornby, A. S. 1989. Oxford Advanced Learner's Dictionary of Current English. 4th ed. Oxford: Oxford University Press.

Leech, Geoffrey. 1974. Semantics. London: Penguin Books Ltd.

Lyons, John. 1977. Semantics. Cambridge: Cambridge University Press.

Oxford Idioms Dictionary for Learners of English. 2006. 2nd ed. Oxford: Oxford University Press.

Palmer, F. R. 1976. Semantics, A New Outline. Cambridge: Cambridge University Press.

Shakespeare, William. 1996. The Complete Works of William Shakespeare. Ware: Wordsworth Editions.

Siefring, Judith. 2004. Oxford Dictionary of Idioms. 2nd ed. Oxford: Oxford University Press. The New Testament of Our Lord and Saviour Jesus Christ, With Psalms. 1976. Ontario: Gideons International. 